\title{
Mitochondrial Encephalomyopathy in Drosophila
}

\author{
Alicia M. Celotto, ${ }^{1,2}$ Adam C. Frank, ${ }^{1,2}$ Steven W. McGrath, ${ }^{1,2}$ Tim Fergestad, ${ }^{3}$ Wayne A. Van Voorhies, ${ }^{5}$ \\ Karolyn F. Buttle, ${ }^{4}$ Carmen A. Mannella, ${ }^{4}$ and Michael J. Palladino ${ }^{1,2}$ \\ ${ }^{1}$ Department of Pharmacology and ${ }^{2}$ Pittsburgh Institute for Neurodegenerative Diseases, University of Pittsburgh School of Medicine, Pittsburgh, \\ Pennsylvania 15261, ${ }^{3}$ Laboratory of Genetics, University of Wisconsin-Madison, Madison, Wisconsin 53706, ${ }^{4}$ Resource for the Visualization of Biological \\ Complexity, Wadsworth Center, New York Department of Health, Albany, New York 12201, and ${ }^{5}$ New Mexico State University, Molecular Biology Program, \\ Las Cruces, New Mexico 88003
}

Mitochondrial encephalomyopathies are common and devastating multisystem genetic disorders characterized by neuromuscular dysfunction and tissue degeneration. Point mutations in the human mitochondrial ATP6 gene are known to cause several related mitochondrial disorders: NARP (neuropathy, ataxia, and retinitis pigmentosa), MILS (maternally inherited Leigh's syndrome), and FBSN (familial bilateral striatal necrosis). We identified a pathogenic mutation in the Drosophila mitochondrial ATP6 gene that causes progressive, adult-onset neuromuscular dysfunction and myodegeneration. Our results demonstrate ultrastructural defects in the mitochondrial innermembrane, neural dysfunction, and a marked reduction in mitochondrial ATP synthase activity associated with this mutation. This Drosophila mutant recapitulates key features of the human neuromuscular disorders enabling detailed in vivo studies of these enigmatic diseases.

Key words: ATP6; ANT; ATP synthase; neurodegeneration; muscle degeneration; aging; mitochondria

\section{Introduction}

Mitochondrial impairment results in a host of devastating conditions known generally as respiratory chain diseases (DiMauro and Schon, 2003). Furthermore, mitochondrial dysfunction has been conclusively implicated in nearly every chronic human neurodegenerative disease, including mitochondrial encephalomyopathies, amyotrophic lateral sclerosis, and Huntington's, Alzheimer's, and Parkinson's diseases (Orth and Schapira, 2001; Schon and Manfredi, 2003). Primary mutations in several distinct mitochondrial genes, as well as nuclear genes that encode proteins localized to the mitochondria, are known to cause a variety of related and devastating encephalomyopathies with complex clinical features, including neurological and muscular dysfunction that is often complicated by renal, endocrine, cardiac, and hepatic involvement (for review, see Schapira and Cock, 1999; Hart et al., 2002; DiMauro and Schon, 2003). There are over 150 mutations causing these related diseases and range from

\footnotetext{
Received Sept. 30, 2005; revised Nov. 22, 2005; accepted Nov. 25, 2005.

This work was supported by National Institutes of Health (NIH)-National Institute of Neurological Disorders and Stroke Grant T32NS $07391-07$ (A.M.C.), Pittsburgh Institute for Neurodegenerative Diseases research award (M.J.P.), The Wadsworth Center's Resource for Visualization of Biological Complexity, NIH National Biotechnological Resource Grant RR01219 from the National Center for Research Resources (Department of Health and Human Services, Public Health Service), and the University of Pittsburgh Department of Pharmacology and School of Medicine. We thank Dr. Christian Renken for assistance with tomographic data collection, Matt Levy and the University of Pittsburgh core facilities for assistance with sequencing, the Pittsburgh Center for the Environmental Basis of Human Disease (CEBHD) for support, Dr. Simon Watkins and the Center for Biologic Imaging for access to microscopes and histology equipment, Ana Bursick for sharing her microscopy expertise, Dr. Valerian Kagan for helpful advice, Drs. Michael Ashburner and Michael Clark and the Bloomington Stock Center for fly strains, Dr. lan Reynolds for his ongoing support and numerous helpful discussions, and Dr. Bruce Freeman for comments on this manuscript.

Correspondence should be addressed to Michael J. Palladino, Pittsburgh Institute for Neurodegenerative Diseases and Department of Pharmacology, University of Pittsburgh School of Medicine, 200 Lothrop, Biomedical Science Tower E1355, Pittsburgh, PA 15261. E-mail: mjp44@pitt.edu.

DOI:10.1523/JNEUROSCI.4162-05.2006

Copyright $\odot 2006$ Society for Neuroscience $\quad$ 0270-6474/06/260810-11\$15.00/0
}

point mutations to large deletions. Because there are numerous mutagenic targets, these mitochondrial disorders have an extremely high prevalence similar to that of muscular dystrophy, $\sim 10-15$ cases per 100,000 individuals (DiMauro and Schon, 2003).

Point mutations in the human mitochondrial ATP6 gene are known to cause neuropathy, ataxia, and retinitis pigmentosa (NARP), maternally inherited Leigh's syndrome (MILS) and familial bilateral striatal necrosis (FBSN) diseases. Also, disease is associated with a common $5 \mathrm{~kb}$ mitochondrial genome deletion of ATP6 (Table 1). The ATP6 protein is an essential component of the mitochondrial $\mathrm{F}_{1} \mathrm{~F}_{0}$-ATP synthase (Complex V) that functions as a hydrogen ion channel serving to couple ion transport with rotary ATP catalysis (Mitchell and Moyle, 1967; Walker, 1995; Boyer, 1997; Stock et al., 2000). Bioenergetic impairment and oxidative damage resulting from respiratory chain dysfunction are two prominent hypotheses for the pathogenesis of human mitochondrial encephalopathies. However, mechanistic details of pathogenesis associated with chronic mitochondrial impairment remain unclear, and as a result, therapeutic approaches remain limited.

Autosomal dominant progressive external ophthalmoplegia (adPEO) results from mutation of three distinct nuclear loci: 4q34-35, 10q24 (Suomalainen et al., 1995), and 15q22-26 (Van Goethem et al., 2001). The 4q PEO locus was recently identified as the ANT1 gene, wherein four different mutation sites segregating in six PEO families were discovered (Kaukonen et al., 2000; Napoli et al., 2001; Komaki et al., 2002). Patients with PEO are predisposed to secondary mitochondrial mutations that appear to underlie, or at least contribute to, the pathophysiological basis for their degenerative disease (Servidei et al., 1991; Suomalainen et al., 1997). The basis for the mutator phenomenon associated with PEO disease is not understood. 
Table 1. Human diseases associated directly with ATP6 mutation

\begin{tabular}{|c|c|c|c|}
\hline $\mathrm{AA}$ & Mutation & Disease & Notes and key references \\
\hline S99P & T8821C & Oligospermia & Holyoake et al., 1999 \\
\hline W109R & T8851C & FBSN & De Meirleir et al., 1995 \\
\hline L156R & T8993G & NARP/MILS/HCM & Holt et al., 1990; Fryer et al., 1994; Pastores et al., 1994; White et al., 1999; Marin-Garcia et al., 2001 \\
\hline L156P & T8993C & NARP/MILS & de Vries et al., 1993; Santorelli et al., 1994; White et al., 1999; Sciacco et al., 2003 \\
\hline I192T & T9101C & LHON & Not a highly conserved residue or dramatic amino acid change (Lamminen et al., 1995) \\
\hline L217P & T9176C & FBSN//MILS & Thyagarajan et al., 1995; Campos et al., 1997 \\
\hline L217R & T9176G & MILS & Carrozzo et al., 2001 \\
\hline N/A & Deletion & PEO & Commonly removes ATP6 (Moraes et al., 1989; Schon et al., 1989; Zeviani et al., 1989; Mita et al., 1990) \\
\hline N/A & Deletion & KSS & Commonly removes ATP6 (Moraes et al., 1989; Schon et al., 1989; Mita et al., 1990) \\
\hline N/A & Deletion & Myopathy & Commonly removes ATP6 (Holt et al., 1989) \\
\hline
\end{tabular}

NARP is a single disease defined by different authors as either neuropathy, ataxia, retinitis pigmentosa or neurogenic muscle weakness, ataxia, retinitis pigmentosa. HCM, Hypertrophic cardiomyopathy; KSS, Kearns-Sayre syndrome; LHON Leber hereditary optic neuropathy.

We discovered a mitochondrial ATP6 mutation as a maternally inherited component in our Drosophila ses $B^{1}$ (ANT1) mutant stock. To our knowledge this is the first pathogenic mitochondrial mutation isolated in an intact genetic animal system. Our studies of the Drosophila ATP6 ${ }^{1}$ and $\operatorname{ses} B^{1}$ (ANT1) mutations revealed common phenotypes, including conditional paralysis, shortened lifespan, and degeneration of the neuromuscular system. The observed locomotor impairment, myodegeneration, neural dysfunction, and severe shortening of lifespan observed in the fly recapitulate key features of MILS disease in humans. Ultrastructural analysis of $A T P 6^{1}$ revealed a novel mitochondrial morphological defect associated with ATP synthase impairment. ATP synthase activity was absent in $A T P 6^{1}$ mutants. Surprisingly, respiration rates were unaltered in these mutants. These data demonstrate that impaired ATP synthase function associated with ATP6 dysfunction can cause severe encephalomyopathy in the absence of a defect in respiration rate in vivo.

\section{Materials and Methods}

Drosophila stocks and culture. Standard cornmeal molasses fly media was used, unless otherwise noted. $s e s B^{1}$ and DSR (Wolbachia-infected positive control) flies were obtained from Michael Ashburner (University of Cambridge, Cambridge, UK) and Michael Clark (University of Chicago, Chicago, IL), respectively. All other stocks were obtained from the Bloomington stock center. Canton S was our wild-type (WT) strain. Tetracycline treatment of flies involved maintaining cultures on standard media supplemented with $0.25 \mathrm{mg} / \mathrm{ml}$ tetracycline for two generations, as described previously (Min and Benzer, 1997b).

Lifespan and behavior analysis. Lifespan analysis was performed as described previously (Palladino et al., 2003). Mechanical sensitivity ("bang sensitivity") was assayed by vortexing flies in a standard media vial for $20 \mathrm{~s}$ and measuring the length of paralysis, similar to a previously described protocol (Ganetzky and $\mathrm{Wu}, 1982$ ).

Genetic mapping of $\mathrm{MAT}^{\mathrm{BS}}$. $\operatorname{ses} B^{1} / \operatorname{ses}^{1}$ females mated with wild-type males produce exclusively bang-sensitive paralytic offspring, suggesting that $\operatorname{ses} B^{1}$ may be dominant for this phenotype. $\operatorname{ses} B^{1} / \mathrm{Y}$ males mated with wild-type females never produce paralytic offspring, suggesting that $\operatorname{ses} B^{I}$ may be recessive for this phenotype. This conundrum prompted us to mate affected $s e s B^{1} / F M 7 a$ females with $F M 7 a$ males, and $\operatorname{ses} B^{1} / Y$ males mated with $C(1) / Y$ females (compound first chromosome with two ses $B^{+}$chromosomes attached to one centromere). The former mating yielded genotypically $F M 7 a / F M 7 a\left(\operatorname{ses} B^{+} / \operatorname{ses}^{+}\right)$animals with locomotor impairment. These animals were out-crossed to wild-type animals for two generations maintaining maternal inheritance while selecting against the FM7a chromosome to produce our MAT $T^{B S}\left(A T P 6^{1}\right)$ stock. The latter yielded $\operatorname{ses} B^{I} / \mathrm{Y}$ animals completely lacking a maternal $\operatorname{ses} B^{I}$ $\left(M A T^{B S}\right)$ contribution and were used to generate a $\operatorname{ses} B^{1}, \mathrm{MAT}^{+}$strain (patriclinously cleaned).

Determining percentage of homoplasmy. Using subsaturating PCR conditions, we amplified the ATP6 gene from three independent mutant and control whole genomic DNA preparations and subcloned the $\sim 500 \mathrm{bp}$ fragment into a TOPO T/A vector (Invitrogen, Carlsbad, CA). From each of the three independent $A T P 6^{1}$-derived transformations, we isolated plasmid from $\sim 30$ clones and determined whether they were mutant (Fok I-resistant) or wild type (Fok I-liable) by restriction digestion and visualization on an ethidium bromide-stained agarose gel. We similarly examined 30 clones, 10 each from three independent wild-type control experiments, to assess the frequency of Fok I-resistant clones in wild-type control flies. We never observed a Fok I-resistant clone from wild-type control flies.

Paraffin histology. Heads were removed, probosci were dissected away, and heads were fixed overnight in Carnoy's fixative as described previously (Palladino et al., 2002). Bodies were dissected so that only the thorax remained, which were fixed overnight in Carnoy's fixative. Sections $(5 \mu \mathrm{m})$ were stained with hematoxylin and eosin (H\&E) using standard methods.

Transmission electron microscopy. Animals were aged to day 10, and their brains were dissected and processed similar to methods described previously (Kawasaki et al., 1998). Briefly, fixation occurred overnight at $4^{\circ} \mathrm{C}$ in a buffered saline solution containing $2.5 \%$ paraformaldehyde and $1.5 \%$ gluteraldehyde (the primary fixative). Brains were postfixed in $1 \%$ osmium tetroxide solution, dehydrated in a graded ethanol series, and embedded in epon resin. Sections $(65 \mathrm{~nm})$ were obtained from a Reichert Ultracut ultramicrotome and stained with $4 \%$ uranyl acetate and 2.7\% lead citrate. The tissue was imaged on a JEOL (Akishima, Japan) 100CX transmission electron microscope. Stereological protocols were followed to collect numerous images from the central brain (neuropil) and the brain periphery (rich in cell bodies) from day 10 mutants and wild-type controls. Randomly selected central brain micrographs were used to quantify the frequency of aberrant mitochondria. The evaluator, blinded to the genotype, was asked to count and characterize the morphology of mitochondria from six micrographs $\left(711 \mu \mathrm{m}^{2}\right.$ area per genotype). A Student's $t$ test was used to evaluate significance.

Three-dimensional electron imaging: high-voltage electron tomography. For tomography, 180- to 310-nm-thick sections were cut from the epon blocks, and colloidal gold particles ( $15 \mathrm{~nm}$ diameter) were applied to one side as alignment markers. Tomographic data sets were collected on two electron microscopes. Tilt series were recorded on an AEI EM7 highvoltage electron microscope operated at an accelerating voltage of 1000 $\mathrm{kV}$. The images were recorded around two orthogonal tilt axes, each over an angular range of $\pm 60^{\circ}$ with a $2^{\circ}$ tilt interval. Also, single-axis data sets were collected over an angular range of $\pm 70^{\circ}$ with a $1^{\circ}$ tilt interval on a Tecnai F20 electron microscope (FEI Company, Hillsboro, OR) operated at $200 \mathrm{kV}$. Images were aligned as described previously (Penczek et al., 1995), and tomographic reconstructions were calculated by the weighted back-projection method (Radermacher, 1992); all procedures were implemented in the SPIDER image processing system (Frank et al., 1996). Three-dimensional models of membrane surfaces were generated by density threshold analysis, using Iris Explorer (NAG, Downers Grove, IL) after filtering the volume by anisotropic diffusion (Frangakis and Hegerl, 2001) using SPIDER and masking the mitochondrial outlines in Sterecon (Marko and Leith, 1996). In all cases, the $z$-dimension (section thickness) 
of the final models was increased by $20 \%$ to compensate for radiationinduced thinning of the plastic section (Deng et al., 1999).

ATP synthase assays. The micromolar quantity of ATP produced per microgram of protein was determined using a modified version of a previously described assay (Manfredi, 2001). Mitochondria were isolated from $\sim 2 \mathrm{~g}$ of adult flies. Flies were homogenized with a glass Dounce homogenizer, three passes with plunger $\mathrm{A}$, in $50 \mathrm{ml}$ of mitochondrial isolation buffer (320 mm sucrose, $1 \mathrm{~mm}$ EDTA K-salt, $10 \mathrm{~mm}$ Tris, $\mathrm{pH}$ 7.4). The homogenate was centrifuged at $1500 \times g$ for $10 \mathrm{~min}$ at $4^{\circ} \mathrm{C}$. The supernatant was homogenized, three passes with plunger $\mathrm{B}$, and centrifuged at $17,000 \times g$ for $10 \mathrm{~min}$ at $4^{\circ} \mathrm{C}$. The mitochondrial pellet was resuspended in ATP synthesis buffer A ( $150 \mathrm{~mm} \mathrm{KCl,} 25 \mathrm{~mm}$ Tris-HCl, 2 mм EDTA, $0.1 \%$ BSA, $10 \mathrm{~mm} \mathrm{KH}_{2} \mathrm{PO}_{4}, 0.1 \mathrm{M} \mathrm{MgCl}$, pH 7.4). Each sample is split into two tubes, and each tube contains the following concentrations of reagents (in $\mathrm{mm}$ ): $0.15 \mathrm{di}$ (adenosine)pentaphosphate, 0.1 ADP, 1 malate, and 1 pyruvate. Oligomycin at $10 \mu \mathrm{g} / \mathrm{ml}$ was added to only one of the two tubes. An ATP standard curve was generated $(0.0$, $0.01,0.1,1.0$, and $10.0 \mu \mathrm{M})$. ATP synthase measurements were taken in a black 96-well plate after the addition of buffer B (0.8 mM Luciferin, 20 $\mu \mathrm{g} / \mathrm{ml}$ Luciferase, $0.5 \mathrm{M}$ Tris-acetate, $\mathrm{pH} 7.75$ ), and the luminescence was immediately recorded using a Victor2 plate reader (PerkinElmer, Wellesley, MA). The light emitted was integrated for $1 \mathrm{~s}$ every $30 \mathrm{~s}$ for a total of $3 \mathrm{~min}$. The data from this experiment were normalized to the total protein in the sample. The homogenate was brought to a final concentration of $0.1 \mathrm{M} \mathrm{NaOH}$ and sonicated for $10 \mathrm{~s}$ (setting 5 Fisher sonic dismembrator model 100; Fisher Scientific, Houston, TX). The concentration of protein was determined using a colorimetric protein assay reagent (BioRad, Hercules, CA) and a BSA protein standard curve. There was no significant difference in ATP synthase activity between untreated ATP ${ }^{1}$ and oligomycin-treated wild type, demonstrating that the ATP6 protein encoded by the mutant is not simply oligomycin insensitive.

Population respiration rates. We directly measured respiration of $\sim 5 \mathrm{~g}$ of flies ( $\sim 5000$ flies) as the emergence of $\mathrm{CO}_{2}$ in a fixed volume respirometer. The respirometer was a sealed acrylic $3.570 \mathrm{~L}$ box containing a dual wavelength infrared-absorbance analyzer to monitor $\mathrm{CO}_{2}$ concentration between 0 and 10,000 ppm (model 2820; Bacharach, New Kensington, PA) and 30 glass shell vials each containing $8 \mathrm{ml}$ of yeast-free food and $\sim 150$ flies. Cheesecloth was used to confine flies to within the vials while allowing free air exchange. Flies aged $2-10 \mathrm{~d}$ were placed in the respirometer, which was purged with $60 \% \mathrm{~N}_{2}, 40 \% \mathrm{O}_{2}(20 \mathrm{~min})$ to remove $\mathrm{CO}_{2}$ and establish a standard initial $\mathrm{O}_{2}$ concentration. The intake and exhaust ports were sealed, and the $\mathrm{CO}_{2}$ levels were recorded every 2 $\min$ for $5 \mathrm{~h}$. We performed this experiment, sans flies, to determine the integrity of the container and identify any other sources of $\mathrm{CO}_{2}$ : no detectable $\mathrm{CO}_{2}$ was produced in all experiments without flies over the course of $5 \mathrm{~h}$. The mass of the flies was determined immediately after the experiment, and respiration data are presented as $\mathrm{CO}_{2}$ emergence per unit mass (parts per million per gram of fly) as a function of time. The effective respirometer chamber volume (total volume less volume of vials, food, meter, and flies) is $\sim 2.760 \mathrm{~L}$. Experiments were performed alternating wild-type and age-matched mutant flies $(n=4)$.

Individual metabolic measurements. Flies eclosed at room temperature and were placed in a $25^{\circ} \mathrm{C}$ incubator with a $12 / 12 \mathrm{~h}$ photoperiod for at least $48 \mathrm{~h}$ to acclimate to standard metabolic conditions. Resting metabolic rates were measured on flies that were 5-6 d postemergent using methods described previously (Van Voorhies et al., 2003, 2004). Briefly, respiration was measured as the $\mathrm{CO}_{2}$ produced by individual flies maintained in a $2.2 \mathrm{ml}$ glass sealed chamber flushed with $\mathrm{CO}_{2}$-free, watersaturated (100\% relative humidity) air. Gas samples were removed from the chamber with a Hamilton SampleLock syringe (Hamilton, Reno, $\mathrm{NV})$ and directly injected into a $150 \mathrm{ml} / \mathrm{min}( \pm 1 \%)$ standard temperature pressure dry, $\mathrm{CO}_{2}$-free carrier air stream. Flow of the carrier air stream was controlled with a mass flow meter (Sierra Instruments, Monterrey, CA) and was scrubbed of water vapor with a magnesium perchlorate filter before entering into a Li-Cor 6251 carbon dioxide gas analyzer (Li-Cor, Lincoln, NE). The Li-Cor 6251 analyzer has a sensitivity of $<0.1 \mathrm{ppm}$ and an accuracy of $<1 \mathrm{ppm}$. The amount of $\mathrm{CO}_{2}$ produced by each fly was calculated using DATACAN software (Sable Systems International, Henderson, NV). Each fly examined was briefly frozen at $-80^{\circ} \mathrm{C}$, and its mass was determined using a Sartorius (Goettingen, Germany) M2P microbalance. The $\mathrm{CO}_{2}$ gas analysis system was zeroed daily against $\mathrm{CO}_{2}$ free air and calibrated against a 51 ppm certified gas standard (Air Products, Long Beach, CA.). Previous studies have established that $\mathrm{CO}_{2}$ production provides a sensitive and accurate proxy for oxygen consumption in Drosophila melanogaster (Van Voorhies et al., 2004). Results expressed in microwatts/fly are as follows: $19.6 \pm 0.7$ ATP $^{1}$ females, $20.8 \pm 0.9$ wild-type females, $15.7 \pm 0.4$ ATPalpha $^{\text {DTSIRI }}$ (1R1)-positive control females, $15.1 \pm 0.5 \mathrm{ATP} 6^{1}$ males, $13.3 \pm 0.5$ wildtype males, and $10.2 \pm 0.2 \mathrm{ATPalph}^{D T S 1 R 1}$ (1R1)-positive control males (SE provided). Our studies revealed severely reduced respiration in ATPalpha ${ }^{D T S 1 R 1}$ flies that served as a positive control for these studies. ATPalpha ${ }^{D T S 1 R 1}$ are heterozygous for ATPalpha, the Drosophila gene encoding the $\mathrm{Na}^{+} / \mathrm{K}^{+}$ATPase $\alpha$ subunit (Palladino et al., 2003).

\section{Results}

Maternally inherited mutation causes conditional paralysis Mutations affecting ANT1 in Drosophila were originally identified as a stress-sensitive strain of animals $(\operatorname{ses} B)$ that are conditionally paralytic in response to mechanical stress (Homyk and Sheppard, 1977). It was later discovered that $\operatorname{ses} B^{1}$ is an adult viable hypomorphic allele of the gene encoding ANT1 and that null alleles are lethal (Zhang et al., 1999). Previous studies have shown that conditional paralytic mutants in Drosophila are enriched for those that cause neurodegeneration (Palladino et al., 2002). During the course of studying $\operatorname{ses} B^{1}$ (ANT1), a separate maternally inherited genetic component was discovered that enhances the conditional paralysis of $\operatorname{ses} B^{l}$ (ANT1) and itself causes conditional paralysis. This maternal component was genetically isolated and named for the maternally derived phenotype $M A T^{B S}$ (maternal isolate, bang sensitive; see Materials and Methods for details). $M A T^{B S}$ animals transmit conditional paralysis and reduced lifespan (with 100\% penetrance) to every strain tested but only when maternal inheritance is maintained. The maternal effect is stable; $M A T^{B S}$ strains have been maintained for numerous generations without phenotypic erosion.

Previous studies have shown that a pathogenic variant of the bacterium Wolbachia, a naturally occurring insect symbiont, could infect Drosophila and cause a shortening of lifespan (Min and Benzer, 1997b). To test whether a pathogenic variant of Wolbachia could be the source of the $M A T^{B S}$ maternally inherited phenotypes, Wolbachia-specific primers and an established PCR detection protocol were used as an assay for the presence of these bacteria (Min and Benzer, 1997b). Wolbachia were detected in a positive control strain known to harbor the bacteria but were not present in our mutant strain (data not shown). Furthermore, tetracycline treatment for two generations has been shown to completely rid flies of microbial parasites, including Wolbachia, and this treatment did not modify the phenotypes associated with $M T^{B S}$ (Min and Benzer, 1997b). The strict maternal inheritance and antibiotic resistance of the $M A T^{B S}$ phenotypes led us to hypothesize that there was a mitochondrial mutation in this strain of flies.

\section{$M A T^{B S}$ animals have a mitochondrial mutation in their ATP6 gene}

The mitochondrial genome was amplified in overlapping $\sim 3 \mathrm{~kb}$ fragments using PCR and directly sequenced from our $M A T^{B S}$ and two wild-type control strains. tRNA and rRNA sequences revealed no changes. One nonpolymorphic change in the coding regions was discovered that was unique to the $M A T^{B S}$ strain. Interestingly, this $\mathrm{G}$ to $\mathrm{A}$ transition appeared homogeneous in the sequence chromatogram and results in a glycine to glutamate codon change at position 116 in the ATP6 gene (supplemental 


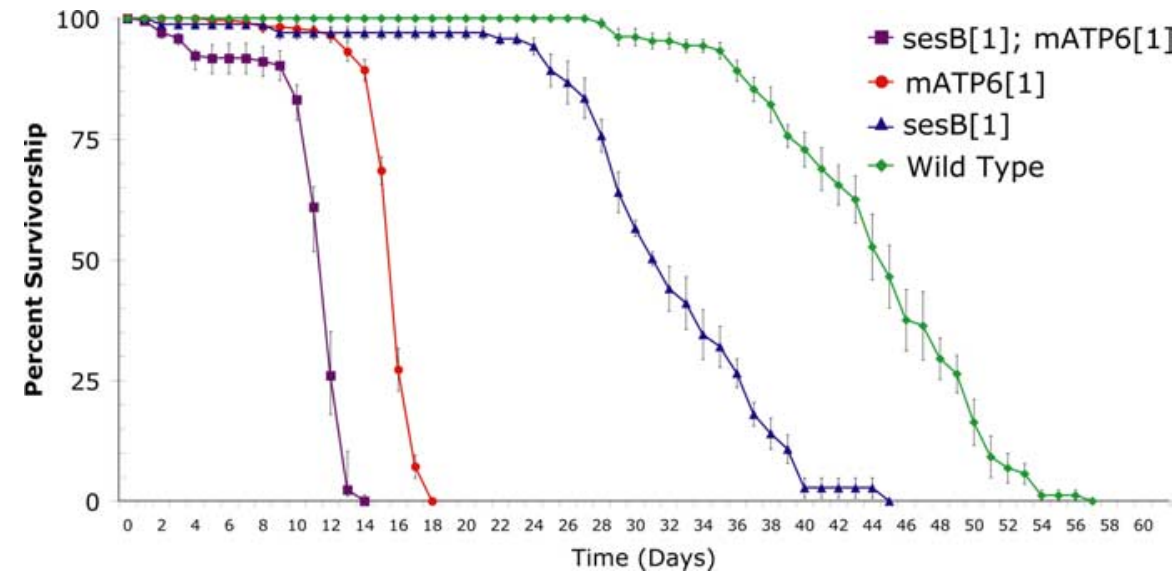

Figure 1. Lifespan analysis of mitochondrial mutants. $\operatorname{ses}^{1}$ (ANT; blue) and $A T P 6^{1}$ (red) mutant flies have a 31 and $67 \%$ reduction in median lifespan from wild-type control animals (WT; green), respectively. Flies bearing both ses $B^{1}$ (ANT) and $A T P 6^{1}$ mutations (purple) have an additional reduction in lifespan: $76 \%$ reduction in median lifespan from control. All comparisons are based on six populations of each genotype. All mutant median lifespans are significantly reduced from wild type (Student's $t$ test; $p<0.001)$. Error bars represent SEM.

Fig. 1, available at www.jneurosci.org as supplemental material). Alignment of the ATP6 amino acid sequences revealed that the glycine residue is invariant in insects and mammals. We have renamed $M A T^{B S}$ as $A T P 6^{1}$. The $A T P 6$ gene encodes an essential subunit of the mitochondrial $\mathrm{F}_{1} \mathrm{~F}_{0}$-ATP synthase (Complex V), which is localized to the inner mitochondrial membrane. Specifically, ATP6 is known to function as a hydrogen ion channel that couples ion transport with rotary ATP catalysis (supplemental Fig. $1 E$, available at www.jneurosci.org as supplemental material). ATP6 is a known target for several human disease mutations that result in complex neuromuscular diseases, such as NARP, MILS, and FBSN syndromes (Table 1).

Human ATP6 mutations that affect several well characterized residues cause numerous related neuromuscular diseases. Interestingly, each of these mutations is aphenotypic when present at low heteroplasmic levels but results in disease when at high levels. For example, one of the best-studied ATP6 mutations, which results in an L156R substitution, is generally aphenotypic when below $\sim 70 \%$ heteroplasmy but causes NARP disease when $\sim 70$ $90 \%$ heteroplasmic (Tatuch et al., 1992). NARP is characterized by adult-onset progressive wasting, neurogenic muscle weakness, and neuropathy. However, when the same mutation is present with greater than $\sim 90 \%$ heteroplasmy, a much more severe disease, MILS, typically results (Schon et al., 2001). MILS is a devastating multisystem childhood syndrome with an extremely poor prognosis. Like many mitochondrial encephalomyopathies, NARP and MILS are complex diseases characterized by a variety of complications resulting from renal, digestive, and cardiac system impairment. The chromatographic data suggest that the ATP $^{1}$ transition is nearly homoplasmic (supplemental Fig. $1 A$, available at www.jneurosci.org as supplemental material). Although heterozygosity can often be seen in chromatographic data, such findings are not strictly quantitative and cannot be used to accurately measure heteroplasmy. To more precisely quantify the frequency of the $A T P 6^{1}$ mutation, $90 A T P 6^{1}$-derived clones from three independent experiments were examined and revealed a $98 \pm 2 \%$ mutant sequence. A similar analysis of 30 wild-type-derived clones from three independent experiments revealed that $100 \pm 0 \%$ of the clones contained the predicted wild-type sequence. These data demonstrate that the $A T P 6^{1} \mathrm{mu}-$ tation is nearly, but not completely, homoplasmic in the fly.
$A T P 6^{1}$ animals have shortened lifespans and tissue degeneration

It is intriguing that the $A T P 6^{1}$ mutation was discovered in the $\operatorname{ses} B^{1}$ (ANT1) mutant genetic background and that each mutation results in a qualitatively similar conditional paralysis phenotype. Lifespan analyses revealed that both $\operatorname{ses} B^{1}$ (ANT1) and $A T P 6^{1}$ animals have a significant reduction in lifespan from wild-type controls (Fig. 1). Despite the similar paralysis phenotype, each mutant strain's lifespan impairment was distinct: $A T P 6^{1}$ and $\operatorname{ses} B^{1}$ median adult lifespan was 12 and $25 \mathrm{~d}$, respectively, whereas control animals' median lifespan was $\sim 50 \mathrm{~d}$. The lifespan of the $A T P 6^{1}$; ses $B^{1}$ double mutants revealed an additional impairment of adult viability beyond each of the individual mitochondrial mutants (Fig. 1). It is important to note that $A T P 6^{1}$ does not appear to compensate for the $\operatorname{ses} B^{1}$ mutation and improve viability.

Mitochondrial dysfunction is known to manifest as neurological and muscular impairment in animals because of the intense metabolic demands of myofibrils and neurons. Furthermore, several Drosophila mutants with shortened lifespan have been characterized and have been found to result in neurodegeneration (Kretzschmar et al., 1997; Min and Benzer, 1997a, 1999; Rogina et al., 1997; Palladino et al., 2002, 2003). Thus, to test whether neuropathology may be causing the reduction in the $A T P 6^{1}$ median lifespan, mutant brains were examined for neurodegeneration using standard paraffin histology and H\&E staining procedures. There were no apparent histologic abnormalities in aged $A T P 6^{1}$ mutants (Fig. 2). However, severe neuropathology was observed in aged ANT $\left(\operatorname{ses} B^{1}\right)$ and $A T P 6^{1}$; $s e s B^{1}$ double mutant brains (Fig. 2). In all genotypes examined, young animals were free of pathology, demonstrating the neurodegeneration is strictly progressive (data not shown). Although $A T P 6^{1}$ mutants do not have obvious neurodegeneration, the mutation dramatically accelerates the onset of severe neuropathology in $\operatorname{ses} B^{1}$ (ANT1) mutants from days 23 to 12 (Fig. $2 B, C$ ). Day 12 ses $B^{1}$ (ANT1) mutants did not exhibit neurodegeneration and were indistinguishable with age-matched $A T P 6^{1}$ mutants and aged wild-type flies (data not shown). NARP and MILS diseases are associated with profound neuromuscular impairment, prompting examination of muscle integrity in $A T P 6^{1}$ mutants. Histology was performed to examine the dorsal flight muscles for the presence of pathology in young and aged animals using standard paraffin histology and (H\&E) staining procedures, which revealed muscle degeneration in $A T P 6^{1}$ mutants that was strictly progressive (Fig. $3 A$ ). Young animals revealed no evidence of myopathology in $A T P 6^{1}$, ses $B^{1}$ (ANT1), or wild-type controls. In contrast, $A T P 6^{1}$ mutants revealed striking pathology at day 10 , a time consistent with the onset of poor viability (Figs. 1, 3A). Day $5 A{ }^{1} 6^{1}$ mutants have less severe myopathology. In contrast, $s e s B^{1}$ (ANT1) mutants revealed only minimal evidence of myopathology by day 10; however, this mutant strain had marked myopathology by day 22 (Fig. 3A). Examination of the thoracic ganglion, which comprises another significant portion of the fly's CNS, revealed age-dependent neurodegeneration in ses $B^{1}$ (ANT1) mutants (Fig. 3B). ATP6 $6^{1}$ mutant histopathology revealed some evidence of thoracic ganglion neurodegeneration, 
namely individual large vacuolar structures that were not observed in age matched wild-type animals (Fig. $3 B$ ). As seen in the brain, the $A T P 6^{1}$ mutant results in neural dysfunction and accelerates ses $B^{l}$ degeneration of the thoracic ganglion (supplemental Fig. 2, available at www.jneurosci.org as supplemental material). It is intriguing that $\operatorname{ses} B^{l}$ (ANT1) mutation results in severe neuromuscular pathology and $A T P 6^{1}$ mutation results predominantly in muscle pathology, yet both mutants are predicted to disrupt mitochondrial ATP output and cause a similar locomotor impairment.

\section{Locomotor impairment in mitochondrial mutants}

One hallmark of mitochondrial encephalomyopathies is the progressive onset of symptoms, including locomotor impairment. Both sesB $B^{l}$ (ANT1) and $A T P 6^{1}$ mutants have reduced locomotor function and conditional paralysis brought on by mechanical stress. We characterized the time required for recovery from physical stress in both mitochondrial mutants. Wild-type flies are relatively unaffected by this stress and recover within $\sim 2-3 \mathrm{~s}$ at all time points examined. There is a small but significant decrement with age in wildtype animals observed using this assay, as seen by comparing day 2 and day 24 animals (Fig. 4) $(p<0.05)$. In contrast, both sesB $B^{l}$ (ANT1) and $A_{T P 6}{ }^{1}$ mutants revealed a markedly progressive paralysis phenotype. Young mutants, day 2 and 4, are not more affected by mechanical stress than wild type $(p>0.05)$, although there is greater variability in recovery time in the mutants than age-matched wild-type animals. However, by day 6, both mitochondrial mutants demonstrate significant locomotor impairment (Fig. 4). The trend continues for $\operatorname{ses}^{1}$ (ANT1) mutants at day 24 , in which paralysis typically lasts $\sim 3$ min. Interestingly, $A T P 6^{1}$; ses $B^{1}$ dou-

ble mutants revealed enhanced locomotor impairment with an earlier onset than either of the separate mitochondrial mutants.

\section{Transmission electron microscopy analysis reveals mitochondrial pathology}

The $\mathrm{F}_{1} \mathrm{~F}_{0}$ ATP synthase (Complex V) uses the mitochondrial electrochemical potential in the form of a hydrogen ion gradient to drive rotary catalysis of ATP. Mutations affecting ATP6, the hydrogen ion channel through which dissipation of this gradient is coupled to ATP production, are thought to have a profound affect on mitochondria function (Mitchell and Moyle, 1967; Walker, 1995; Boyer, 1997; Stock et al., 2000). Mitochondrial dysfunction is known to manifest as neurological and muscular impairment in animals because of the intense metabolic demands of these tissues. The $A T P 6^{1}$ mutation causes severe progressive muscle degeneration but not marked neurodegeneration. It does,
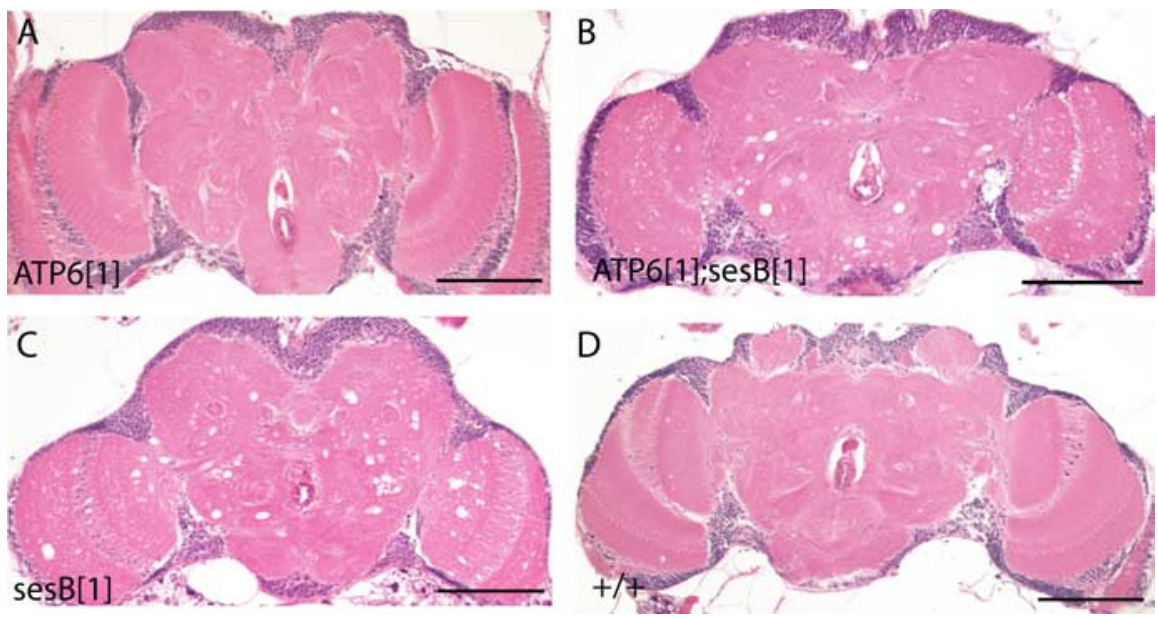

Figure 2. Neuropathology in Drosophila mitochondrial mutants. H\&E-stained midbrain frontal sections from $A T P 6^{1}$ day $14(\boldsymbol{A})$, and $\operatorname{ses}^{1}$ (ANT1) mutants show marked vacuolar pathology throughout the central brain and optic lobes. This analysis did not pathology (data not shown). $n \geq 15$ animals per genotype. Scale bar, $100 \mu \mathrm{m}$.

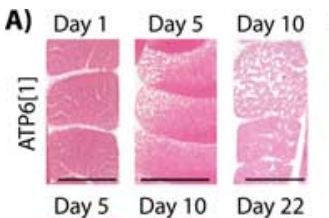

B) Day 1

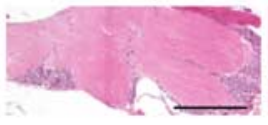

Day 5
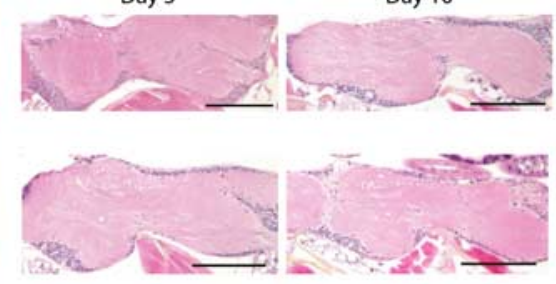

Day 10

Day 5
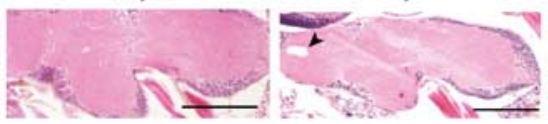

Day 22
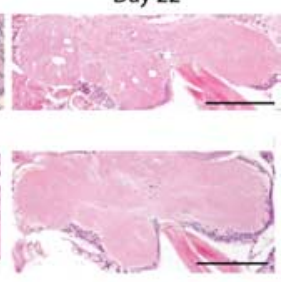

Figure 3. Progressive neuromuscular pathology in Drosophila mitochondrial mutants. Cross sections of dorsal flight muscles $(\boldsymbol{A})$ and longitudinal sections of the thoracic ganglion $(\boldsymbol{B})$ were examined. $\boldsymbol{A}$, ATP6 $^{1}$ mutants (top) revealed severe progressive degeneration of myofibrils in day 5 and day 10 animals that was never observed in wild-type controls (bottom). ATP6 ${ }^{1}$ mutants (a) occasional large vacuoles (arrowhead) on day 10 that were not observed in wild-type animals. $\operatorname{ses}^{1}{ }^{1}$ (ANT) and stained with H\&E. In young animals of all genotypes, there is no evidence of neuromuscular pathology. $n \geq 8$ animals per genotype per time point. Scale bars, $100 \mu \mathrm{m}$.

however, enhance the neurodegeneration phenotype of ses $B^{1}$ (ANT1), demonstrating that the underlying dysfunction is present in this tissue. To examine the consequence of this dysfunction without risk of the results being confounded by tissue degeneration, thin sections of the cortical and central brain regions of day $10 \mathrm{ATP}^{1}$ and age-matched control animals were examined using transmission electron microscopy (TEM). The analysis revealed mitochondria displaying highly abnormal internal compartmentalization that was not typical in age-matched wild-type flies (Fig. 5). The numerous small, round cristae ( $~ 50-80 \mathrm{~nm}$ in diameter) give the mitochondria a honeycomb appearance. This was not an isolated or rare finding: the vast majority of mitochondria observed in numerous midbrain micrographs from independent $A T P 6^{1}$ animals had abnormal internal membrane morphology ( $n>40$ micrographs from four independent animals). TEM micrographs were acquired using 


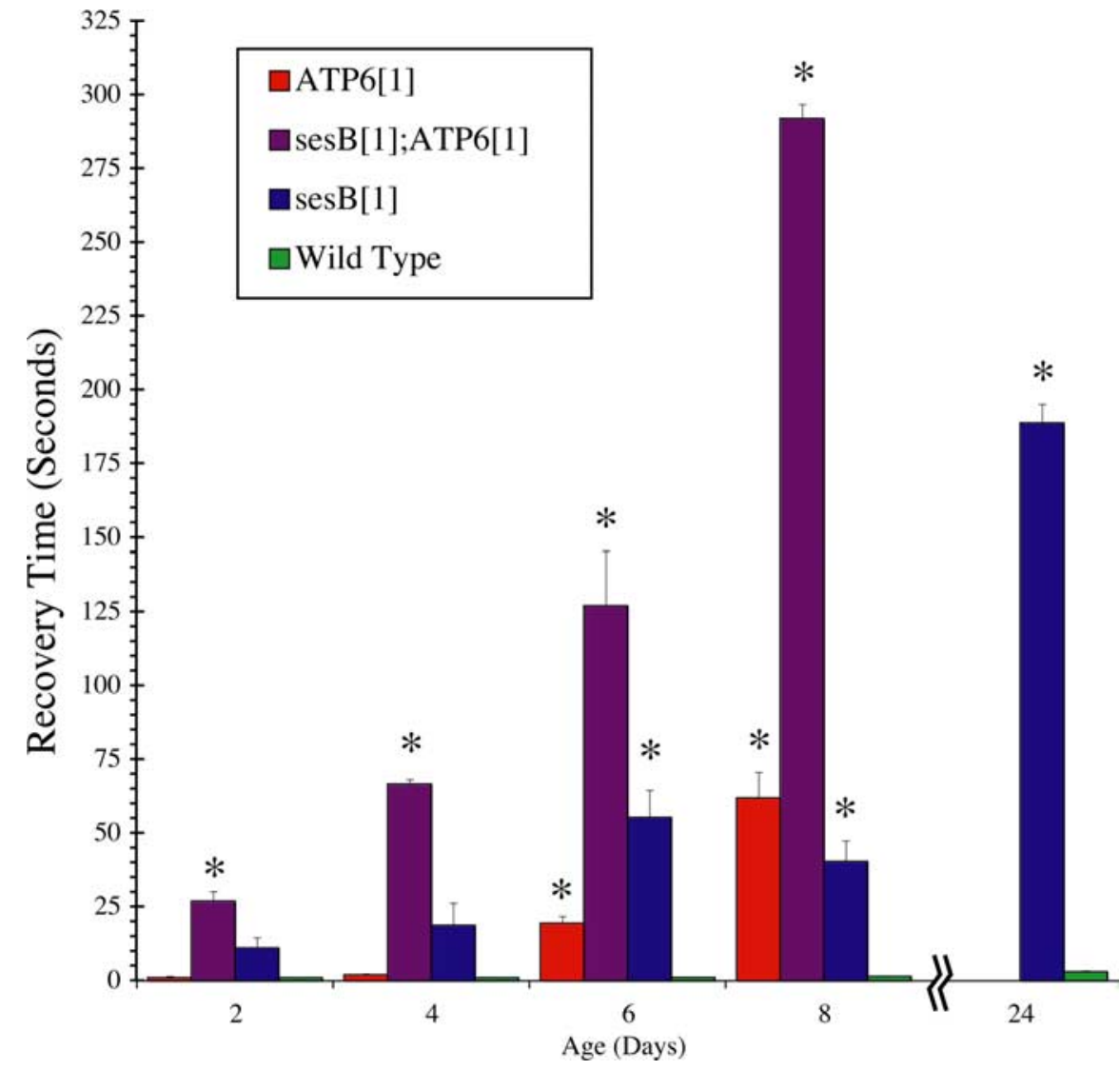

Figure 4. Progressive locomotor impairment in mitochondrial mutants. Locomotor impairment is quantified as the recovery time from stress-induced paralysis. Mechanical stress/hyperstimulation induces sustained paralysis in ses $B^{1}$ (ANT1; blue) and $A T P 6^{1}$ (red) mutant strains, which increase significantly with age. The ATP6 ${ }^{1}$; ses $^{1}{ }^{1}$ double mutants (purple) show increased severity relative to each individual mutant strain and wild-type flies and exhibit a faster progression of the locomotor impairment. Wild-type animals are extremely tolerant to mechanical hyperstimulation and generally recover within 1 or $2 \mathrm{~s}$ with little increase over time (green). The asterisk indicates significant difference from age-matched wild-type controls (Student's $t$ test; $p<0.01$ ). Error bars represent SEM. Three populations of 15 animals/genotype were tested. $A T P 6^{1}$ and $A T P 6^{1}$; ses $^{1}$ double mutants were not tested beyond day 8 because of morbidity in the populations (Fig. 1).

stereological protocols allowing the frequency of this morphological abnormality to be quantified in a blinded analysis of randomly selected midbrain micrographs covering $711 \mu \mathrm{m}^{2}$ tissue from $A T P 6^{1}$ and wild-type control animals (Fig. 5C). The frequency of abnormally compartmentalized mitochondria was significantly higher in mutant brains and, correspondingly, the frequency of normal mitochondrial was significantly reduced $(p<$ 0.01 ). Although mitochondria are morphologically abnormal, the density (number of mitochondria per unit area) of mitochondria in $A T P 6^{1}\left(31 \pm 3\right.$ per $\left.100 \mu \mathrm{m}^{2}\right)$ is not significantly different from that of wild-type control animals $\left(35 \pm 2\right.$ per $100 \mu \mathrm{m}^{2}$; Student's $t$ test; $p=0.45$ ). Previous ultrastructural examination of mitochondria has revealed the dynamic nature of mitochondrion structure (Hackenbrock, 1966). More recently, tomographic modeling has confirmed the functional importance of the mitochondrial internal membrane, which can become compartmentalized in conditions associated with mitochondrial impairment (Frey and Mannella, 2000).

\section{TEM tomography analysis of $A T P 6^{1}$}

The appearance of small, round cristae in mitochondria of ATP6 mutants is reminiscent of a morphological abnormality associated with a human mitochondrial myopathy, Senger's syndrome (Huizing, 1998; Jordens et al., 2002). In the latter case, three- dimensional imaging of the mitochondria, using electron tomography of thick sections, demonstrated that the round cristae are, in fact, vesicles that are not attached to the inner boundary membrane by the usual crista junctions (Frey and Mannella, 2000). To elucidate the structure of the mitochondrial inner membrane in the Drosophila mutant, we generated tomographic reconstructions of the aberrant $A T P 6^{1}$ mitochondria. The tomographic analysis verified the roughly spherical shape of the cristae in the honeycomb regions of these mitochondria but also revealed a more complex threedimensional structure than was evident by standard TEM analysis. Specifically, the round inner membrane compartments are not individual, unconnected vesicles (as in the case of Senger's syndrome) but rather are part of a highly interconnected membrane network (Fig. 6). The tightly packed spherical compartments are connected by narrow tubular junctions to each other and to the inner boundary membrane (i.e., the region that parallels the outer membrane) (Fig. 6C,D, G). An even more intriguing feature of the tomographic reconstructions is that the roughly spherical compartments are clearly contiguous with the lamellar regions of the inner membrane (Fig. 6E,F). We were unable to find a single unambiguous example of a truly vesicular (unattached) inner membrane compartment within the tomogram, suggesting that the round compartments represent local dilations in the lamellae that remain physically coupled with the rest of the inner-membrane space. At numerous places the lamellar membranes were observed to be fenestrated (evident in Fig. 6E,F). See supplemental movies 1 and 2 (available at www.jneurosci.org as supplemental material) for two independent tomograms of $A T P 6^{1}$ mitochondria, movie 3 (available at www.jneurosci.org as supplemental material) for an animation of the full membrane model of Figure 6, $C$ and $D$, and movie 4 (available at www.jneurosci. org as supplemental material) for a tomogram of wild-type mitochondrion.

\section{Mitochondrial function in $A T P 6^{1}$ mutants}

Mitochondrial encephalomyopathies are collectively an extremely prevalent and devastating class of diseases that can result from a variety of mitochondrial or nuclear mutations. Mitochondrial encephalomyopathies associated directly with ATP6 mutation, namely NARP, MILS, and FBSN, can result from numerous mutagenic events (Table 1) with the resulting disease onset and severity highly dependent on the percentage of homoplasmy of the mutation. The pathological basis of these diseases is uncertain, but it has been hypothesized that bioenergetic impairment and oxidative stress resulting from respiratory chain dysfunction contribute to the disease condition. To test whether the ATP ${ }^{1}$ mutation altered mitochondrial ATP synthase activity in vivo, luciferin-luciferase luminescence assays (Manfredi, 2001) were 
used to biochemically measure the oligomycin-dependent component of ATP generation from $A T P 6^{1}$ mitochondria (Fig. 7A). Wild-type control mitochondria had robust ATP synthase activity (23.3 $\mu \mathrm{mol} / \mathrm{min} / \mathrm{mg}$ ), whereas ATP6 mutant mitochondria never revealed significant ATP synthase activity in this assay (Fig. $7 B)(p<0.01)$. We similarly examined ATP synthase activity from wild-type flies acutely treated with dinitrophenol (DNP). DNP-treated flies produced 6.9 $\mu \mathrm{mol} / \mathrm{min} / \mathrm{mg}$ ATP synthase activity, a significant reduction from untreated wild-type flies $(p<0.05)$. These data demonstrate that ATP synthase function in $A T P 6^{1}$ mutants is markedly reduced and that the resulting bioenergetic impairment likely contributes to disease pathogenesis.

The abnormal morphology of $A T P 6^{1}$ mitochondria and the reduction in mitochondrial ATP synthase activity prompted us to investigate whether an altered rate of respiration in these animals may also be contributing to the disease pathogenesis. The rate of respiration of $A T P 6^{1}$ and agematched wild-type control populations was measured in a fixed volume respirometer. Surprisingly, both genotypes produced an indistinguishable linear response (Fig. 7C). The respiration rate was derived from the slope of the best-fit line and was not different between the ATPG ${ }^{1}$ mutants and controls ( $p=0.68 ; n=4)$. Although these data strongly argue that respiration rate is not affected in the mutant strain, an independent and extremely sensitive single fly assay was used to verify this finding (Van Voorhies et al., 2003, 2004). The resting metabolic rate of individual $A T P 6^{1}$ and age-matched wild-type control flies was measured and, in accord with population measurements, there was no significant difference in metabolic rate between these strains (Fig. $7 D)(p>0.33)$. There was a significant decrease in the respiration rate from a positive control ATPalpha ${ }^{D T S 1 R 1}(1 \mathrm{R} 1)$ strain $(p<0.001)$. These data suggest that our assay of respiration rate is sufficiently sensitive to detect differences in metabolic rate and that there is no apparent dysfunction in respiration rate contributing to the neuromuscular condition in $A T P 6^{1}$ mutant flies.

\section{Discussion}

Mitochondrial encephalomyopathies are a collection of devastating medical conditions that are poorly understood and for which therapeutic treatments remain extremely limited. Our understanding of these mysterious diseases is constrained by our limited ability to genetically manipulate mitochondria, difficulties associated with studying progressive conditions, and a lack of tractable in vivo models that recapitulate these diseases. This is especially true of conditions associated directly with mutation of the mitochondrial genome, such as NARP, MILS, and FBSN. We identified marked neuromuscular degeneration associated with mutations of the nuclear gene ses $B$ that encodes the mitochondrial ANT1 protein. We also isolated a nearly homoplasmic mitochondrial mutation of the mitochondrial ATP6 gene that results in a marked shortening of lifespan, locomotor impairment, and progressive myodegeneration. These studies demonstrate that normal respiration rates are maintained despite a defect in mitochondrial ATP synthase activity. To our knowledge, this ATP ${ }^{1}$ Drosophila mutant is the first isolation of an endogenous mitochondrial mutation that recapitulates key pathological features of human mitochondrial disease. This tractable genetic model of MILS disease will allow detailed studies to further elucidate the pathogenic basis of this disease and related mitochondrial encephalomyopathies.

\section{Mitochondrial morphology and neuromuscular pathology}

Examination of brain mitochondria in $A T P 6^{1}$ mutants revealed a striking morphological defect associated with the neural dysfunction in these mutants. The pathology resulted in mitochondria with a honeycomb appearance that was presumably caused by vesicularization of the inner mitochondrial membrane. More de- 

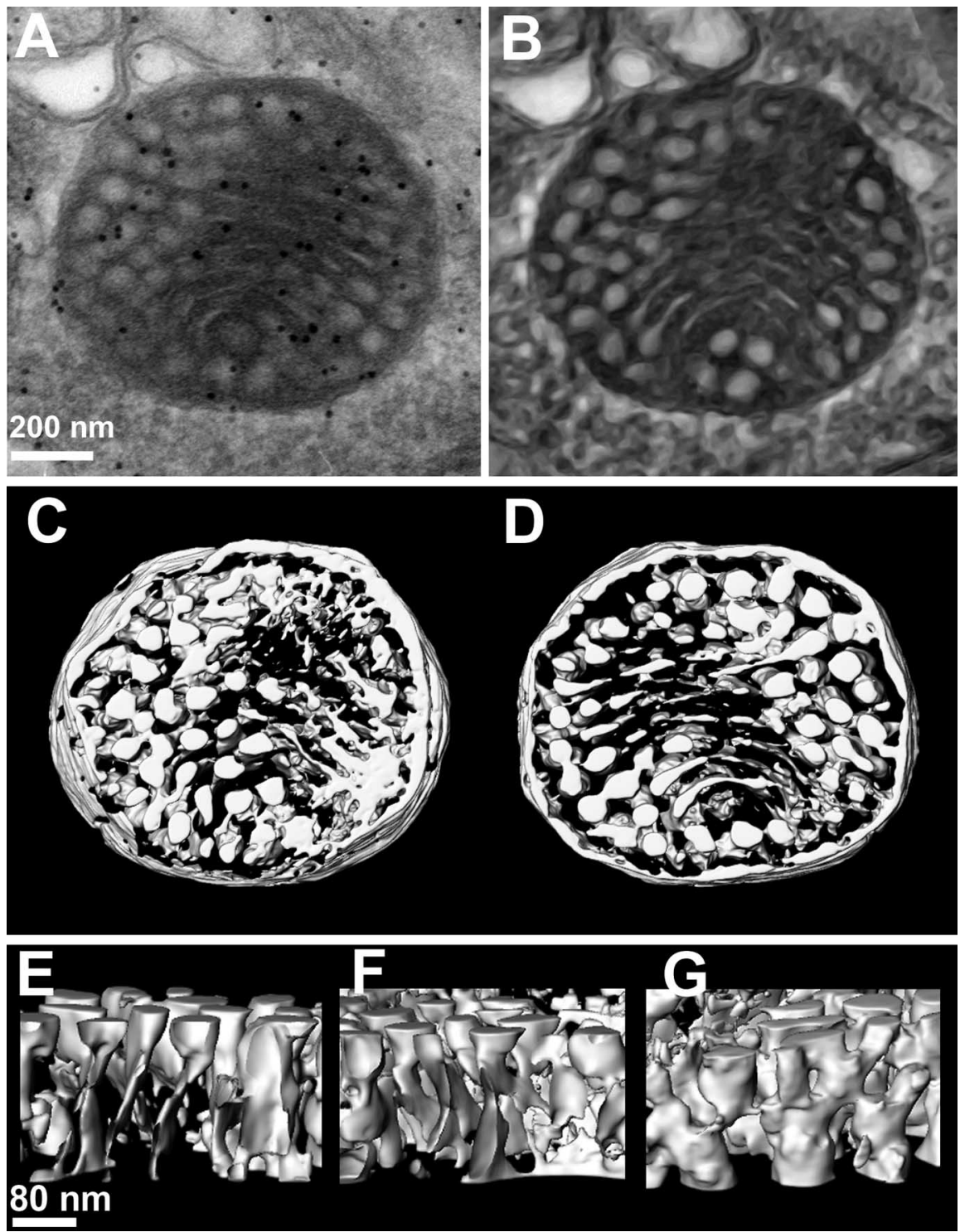

Figure 6. Tomography TEM analysis of $A T P 6^{1}$ mitochondrial innermembranes. Day $10 A T P 6^{1}$ central brain mitochondria were examined using electron tomography. $\boldsymbol{A}$, Projection image of an untilted thick section $(\sim 0.2 \mathrm{~mm})$ of a typical mitochondrion shows a honeycomb appearance similar to that in Figure $6 B$; numerous colloidal gold particles used for alignment are evident in the field. $\boldsymbol{B}$, A representative slice, $2 \mathrm{~nm}$ thick, from the center of the tomogram reconstructed from 122 tilted views of the mitochondrion in $\boldsymbol{A}$. $\boldsymbol{C}-\boldsymbol{G}$, Volume-rendered models of the tomogram reveal complex inner membrane compartmentalization. For clarity, the model is split into top $(1-36 ; \boldsymbol{C})$ and bottom $(37-72 ; \boldsymbol{D})$ halves that each reveal an extensively interconnected network of inner membrane compartments. The round compartments are contiguous at numerous sites with lamellae and the intermembrane space. Removing the outer and peripheral inner membranes from the model and clipping it along various planes clearly reveals the transitions between the round, vesicle-like regions and the curving lamellar regions within the inner mitochondria membrane $(\boldsymbol{E}, \boldsymbol{F})$. The interconnectedness of the compartments is revealed by regular forking membranous structures seen in the row of vesicle-like cristae. $\boldsymbol{G}$. Note that the model is oriented in plates $\boldsymbol{E}-\boldsymbol{G}$ such that "up" in these side views corresponds to the top surface shown in $\boldsymbol{C}$. Also see supplemental movies (available at www.jneurosci.org as supplemental material) of the entire tomogram.

tailed TEM tomography revealed that the roughly spherical inner membrane compartments were highly interconnected and contiguous with lamellar regions of the mitochondrial inner membrane. These findings are especially intriguing because similar (albeit not identical) morphological abnormalities are seen in a human myopathy (i.e., vesicular cristae in Senger's syndrome) (Huizing, 1998) and an avian model system (canary myocardial mitochondria) (Slautterback, 1965; Frey and Mannella, 2000). The ultrastructural similarities among these three diverse systems suggest a conserved underlying pathophysiology and argue that our model system will provide valuable insight into the molecular basis of human mitochondrial diseases. In the case of Senger's syndrome, there is evidence that the disorder is causally linked to a deficiency of ANT1 protein (Jordens et al., 2002) Such a defect could account for both a severe bioenergetic deficit in these patients and altered physical properties of the inner membrane. For example, an inhibitorinduced conformational change in ANT causes aberrant morphology of the inner membrane of isolated liver mitochondria (Scherer and Klingenberg, 1974). Likewise, a mutation in the subunit e of yeast ATP synthase that inhibits dimerization of the protein complex results in abnormal cristae morphology (Paumard et al., 2002). Whether the $A T P 6^{1}$ mutation affects intermolecular interactions of the ATP synthase and whether this might account for the observed abnormality in inner membrane morphology of Drosophila mitochondria will need to be examined.

The rate of mitochondria with aberrant morphology was extremely high $(>60 \%$ of the mitochondria in ATP6 mutants), suggesting widespread dysfunction throughout the brains of these animals. Significant neurodegeneration was not prominent in $A T P 6^{1}$; however, neural dysfunction was evident and dramatically increased the onset of neuropathology in ses $B^{1}$ animals. Severe myopathy was observed in $A T P 6^{1}$ mutants coincident with the onset of morbidity in this strain, suggesting a causal relationship. It is curious that $\operatorname{ses} B^{1}$ (ANT) dysfunction results in neuromuscular pathology and $A T P 6^{1}$ results primarily in myopathy. It is possible that the severe myopathy in $A T P 6^{1}$ results in lethality before the onset of neurodegeneration and that the ultrastructural pathology observed is an early indicator of neuropathogenesis. Although the prevalence of the mitochondrial pathology is extremely high, it does not precisely match the near homoplasmy of the $A T P 6^{1}$ mutation $(98 \%)$. It is possible that the morphological defect represents a more advanced stage of organellar dysfunction and that a small subset of affected (mutant) mitochondria will maintain essentially normal morphology. Alternatively, if one assumes the $A T P 6^{1}$ mutation is fully recessive, only mitochondria in which all of the mitochondrial genomes are mutated would exhibit abnormal morphology. Mitochondria are dynamic polyploid organelles that regularly undergo morphological changes as well as fusion and fission. It is extremely difficult to determine the extent of the polyploidy of mitochondria: estimates range from $\sim 5-25$ genomes per organelle (Satoh and Kuroiwa, 1991; Iborra et al., 2004; Ashley et al., 2005). If the $A T P 6^{1}$ mutation was fully recessive, one would estimate $\sim 60-90 \%$ of the mitochondria would exhibit the mor- 

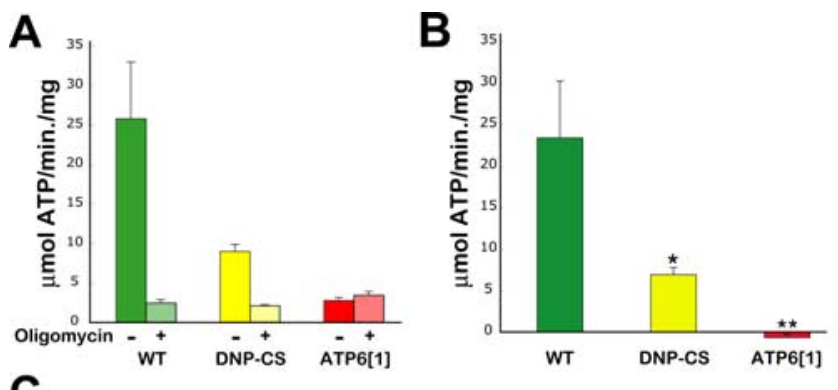

C
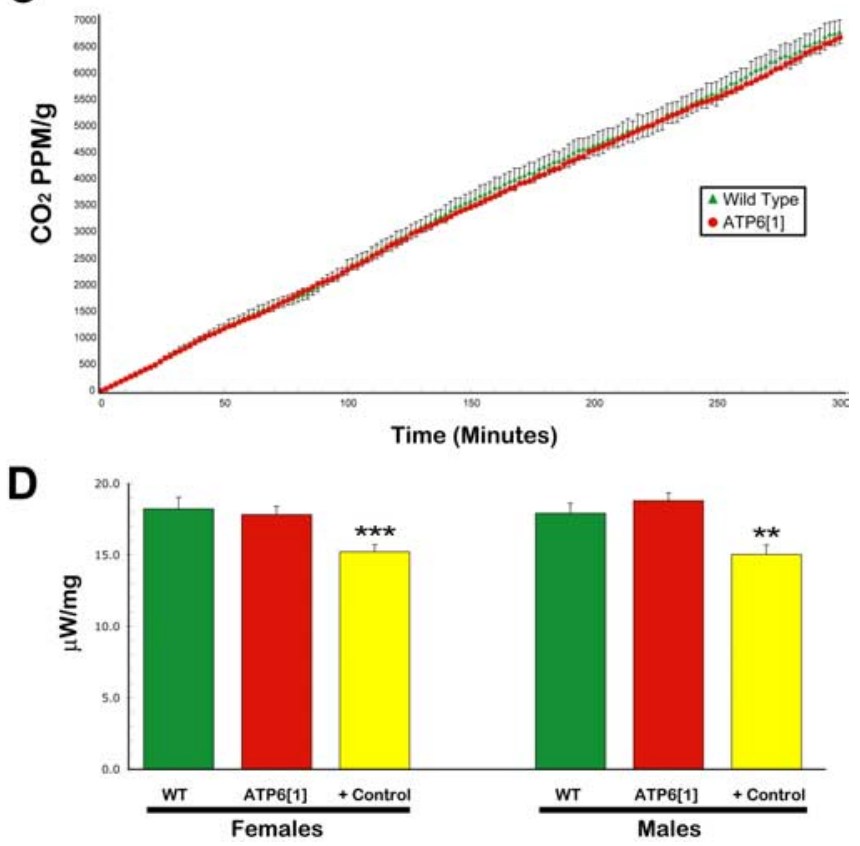

Figure 7. Mitochondrial function is dramatically reduced in ATP6 ${ }^{7}$ mutants. A, ATP synthase activity was measured as the oligomycin-sensitive component of ATP production using a luminescent assay. B, ATP synthase activity per microgram of total mitochondrial protein is significantly lower in $A T P 6^{7}$ and DNP-treated wild-type animals (acute $100 \mathrm{~mm}$ ) compared with wildtype controls (error bars represent SEM; $n>14$ ). C, Metabolic rate was determined for each genotype population as the emergence of $\mathrm{CO}_{2}$ in parts per million in a fixed-volume respiration chamber. Respiration rate for $A T P{ }^{1}$ mutants $(22.1 \mathrm{ppm} / \mathrm{g} / \mathrm{min})$ was no different from wildtype controls ( $22.6 \mathrm{ppm} / \mathrm{g} / \mathrm{min} ; p=0.68)$. Error (SEM) was comparable in both strains; error bars shown are wild-type error $(n=4)$. $\boldsymbol{D}$, Resting metabolic rate was additionally measured from individual $A T P 6^{1}$ mutants and age-matched wild-type controls. There was no difference in rate of respiration between the mutant and wild-type controls ( $p>0.3$ males; $p>0.7$ females). We also examined a mutant strain with a consistently reduced respiration rate as a positive control. Comparisons of microwatts per fly resulted in the same statistical conclusions as the microwatts per milligram of data presented here. SE is given; $n>15$ per genotype per gender. Statistical significance was determined by Student'st test $\left({ }^{*} p<0.05,{ }^{* *} p<0.01\right.$, and $\left.{ }^{* * *} p<0.001\right)$.

phological defect $(0.98 n \times 100)$, which is in good accord with experimental data. It is intriguing that mitochondria with a general honeycomb appearance were observed in age-matched wildtype brains, albeit at a very low rate. This suggests the dysfunction may result from a normal biological function occurring at an accelerated rate. Possibly the inner membrane vesicularization is the result of excessive or poorly controlled mitochondrial fission, fusion, maturation, or a pathology associated with senescence that prematurely manifests with ATP6 dysfunction.

\section{adPEO and ANT dysfunction}

The discovery of a nearly homoplasmic mitochondrial mutation suggests that ANT dysfunction resulting from ses $B^{1}$ acts as a mu- tator causing mitochondrial DNA instability and that this dysfunction also provides selective pressure for the inheritance of the mutated mitochondrial DNA in germ cells. In human adPEO disease, muscle biopsies from those inheriting ANT mutations reveal mitochondrial deletions by Southern blot analysis demonstrating the mutator effect and resulting DNA instability (Zeviani et al., 1989; Kaukonen et al., 2000). It is not known whether adPEO disease is solely the result of the primary ANT dysfunction or whether it is attributable to the secondary mutations sustained to mitochondrial DNA. Flies with an ANT point mutation $\left(\operatorname{ses} B^{l}\right)$ also have progressive myopathy, as do flies with the $A T P 6^{l}$ point mutation (lacking the primary ANT dysfunction). These findings do not completely resolve, which is causing the myopathy in adPEO patients; however, our data demonstrate that ATP6 mutation alone causes myopathy independent of ANT dysfunction. Our data additionally suggest that point mutations result from ANT dysfunction and that these, unlike large-scale deletions, are heritable and likely selected for in the germ line.

Generating a nearly homoplasmic mitochondrial DNA (mtDNA) point mutation in a Drosophila strain would require selective pressure. This could result from any of the following conditions: (1) the ATP6 mutation improved the overall fitness of the animal (which appears unlikely given our lifespan, locomotor impairment, and histological data), (2) continued selection in the laboratory for the most affected animals in the strain, or (3) selective inheritance such as a meiotic drive system operating in the female germ line of the animals. The latter is supported by experimental data demonstrating selective maintenance of the variant ATP6 (T8993G) mtDNA (Vergani et al., 1999) and selective inheritance during oogenesis (Blok et al., 1997). Interestingly, in MILS disease, a more severe variant of NARP manifests when the mutant heteroplasmy is above $\sim 90 \%$. Yet, these diseases are not extremely rare, as might be predicted. It is an enigma how such high heteroplasmy levels are achieved when the mutations that cause these diseases are predicted to have adverse effects on the cells bearing mitochondria with a high mutation load. The discovery and long-term maintenance of the nearly homoplasmic ATP6 ${ }^{1}$ mutation in vivo and the findings of Blok et al. (1997) support the hypothesis that meiotic drive contributes to the prevalence of these diseases through selection within the female germ cells for mitochondrial mutations.

\section{Disease pathogenesis}

Mitochondrial encephalomyopathies are widely recognized as an important and devastating class of diseases; however, the mechanism of pathogenesis remains controversial. Studies have reported severe oxygen consumption defects (Trounce et al., 1994; Mattiazzi et al., 2004), whereas other studies of the same T8993G mutation did not observe such a defect (Nijtmans et al., 2001). Additionally, studies of ATP synthase activity from cellular models nearly homoplasmic for the T8993G mutation revealed a $\sim 50 \%$ reduction in activity, whereas an Escherichia coli model bearing the analogous mutation abolished all activity (Hartzog and Cain, 1993). More recent studies of the T8993G mutation in cell cybrid models revealed a $\sim 95 \%$ reduction in ATP synthesis and described such a large reduction as a common feature associated with several respiratory chain disease mutations, with the notable exception of the T8993C mutation that revealed only a modest decrease (Pallotti et al., 2004). Nearly homoplasmic ATP6 ${ }^{1}$ mutant Drosophila clearly revealed severe neuromuscular impairment associated with marked decrease in ATP synthase activity similar to that reported by cellular models of human mutations (Hartzog and Cain, 1993). Respiration rates are main- 
tained at normal rates in $A T P 6^{1}$ mutants similar to what was observed by Nijtmans et al. (2001). These data demonstrate that bioenergetic crisis is integral to the pathogenesis of ATP6 dysfunction. Additionally, the finding that mitochondrial respiration rates are unaffected in vivo suggests that the mitochondria may be functionally uncoupled, which may be integral to the pathogenesis in these mutants. Additional studies will be needed to test whether normal rates of respiration indicate normal reactive oxygen species generation to determine whether oxidative stress may also be contributing to the pathogenesis.

In humans, ATP6 dysfunction results in three different diseases with overlapping clinical manifestations; however, differences between these diseases and even between patients diagnosed with the same disease are evident. Thus, the genotype/ phenotype relationship remains ambiguous. It is not evident why numerous mutations all affecting the same biochemical process, presumably resulting in bioenergetic impairment in the affected tissues, result in a veritable plethora of clinical manifestations that are not fully explained by the heteroplasmy of the mutations (Schon et al., 1997; DiMauro and Andreu, 2000). Innovative techniques have been used to model mitochondrial diseases, such as cybrid cellular models derived from affected patient cells (Pallotti et al., 2004; Mattiazzi et al., 2004) and mouse models with mitochondrial DNA that was introduced via embryonic stem cells (Sligh et al., 2000). However, these model systems are difficult to study, and a complete understanding of disease pathogenesis has not emerged. This sentiment was exemplified in a review on mitochondrial encephalomyopathies: "thus far insurmountable problem of obtaining animal models for mtDNA mutations has prevented detailed studies of pathogenesis" (DiMauro and Andreu, 2000). The Drosophila strain reported here will enable additional such detailed studies of pathogenesis associated with ATP6 impairment in vivo.

\section{References}

Ashley N, Harris D, Poulton J (2005) Detection of mitochondrial DNA depletion in living human cells using PicoGreen staining. Exp Cell Res 303:432-446.

Blok RB, Gook DA, Thorburn DR, Dahl HH (1997) Skewed segregation of the mtDNA nt $8993(\mathrm{~T}>\mathrm{G})$ mutation in human oocytes. Am J Hum Genet 60:1495-1501.

Boyer PD (1997) The ATP synthase-a splendid molecular machine. Annu Rev Biochem 66:717-749.

Campos Y, Martin MA, Rubio JC, Solana LG, Garcia-Benayas C, Terradas JL, Arenas J (1997) Leigh syndrome associated with the T9176C mutation in the ATPase 6 gene of mitochondrial DNA. Neurology 49:595-597.

Carrozzo R, Tessa A, Vazquez-Memije ME, Piemonte F, Patrono C, Malandrini A, Dionisi-Vici C, Vilarinho L, Villanova M, Schagger H, Federico A, Bertini E, Santorelli FM (2001) The T9176G mtDNA mutation severely affects ATP production and results in Leigh syndrome. Neurology 56:687-690.

De Meirleir L, Seneca S, Lissens W, Schoentjes E, Desprechins B (1995) Bilateral striatal necrosis with a novel point mutation in the mitochondrial ATPase 6 gene. Pediatr Neurol 13:242-246.

Deng Y, Marko M, Buttle KF, Leith A, Mieczkowski M, Mannella CA (1999) Cubic membrane structure in amoeba (Chaos carolinensis) mitochondria determined by electron microscopic tomography. J Struct Biol 127:231-239.

de Vries DD, van Engelen BG, Gabreels FJ, Ruitenbeek W, van Oost BA (1993) A second missense mutation in the mitochondrial ATPase 6 gene in Leigh's syndrome. Ann Neurol 34:410-412.

DiMauro S, Andreu AL (2000) Mutations in mtDNA: are we scraping the bottom of the barrel? Brain Pathol 10:431-441.

DiMauro S, Schon EA (2003) Mitochondrial respiratory-chain diseases. N Engl J Med 348:2656-2668.

Frangakis AS, Hegerl R (2001) Noise reduction in electron tomographic reconstructions using nonlinear anisotropic diffusion. J Struct Biol 135:239-250.

Frank J, Radermacher M, Penczek P, Zhu J, Li Y, Ladjadj M, Leith A (1996) SPIDER and WEB: processing and visualization of images in 3D electron microscopy and related fields. J Struct Biol 116:190-199.

Frey TG, Mannella CA (2000) The internal structure of mitochondria. Trends Biochem Sci 25:319-324.

Fryer A, Appleton R, Sweeney MG, Rosenbloom L, Harding AE (1994) Mitochondrial DNA 8993 (NARP) mutation presenting with a heterogeneous phenotype including "cerebral palsy." Arch Dis Child 71:419-422.

Ganetzky B, Wu CF (1982) Indirect suppression involving behavioral mutants with altered nerve excitability in Drosophila melanogaster. Genetics 100:597-614.

Hackenbrock CR (1966) Ultrastructural bases for metabolically linked mechanical activity in mitochondria. I. Reversible ultrastructural changes with change in metabolic steady state in isolated liver mitochondria. J Cell Biol 30:269-297.

Hart PE, DeVivo DC, Schapira AHV (2002) Mitochondrial disorders in neurology 2, Ed 2, pp 35-68. Boston: Butterworth Heinemann.

Hartzog PE, Cain BD (1993) The aleu207 $\rightarrow$ arg mutation in F1F0-ATP synthase from Escherichia coli. A model for human mitochondrial disease. J Biol Chem 268:12250-12252.

Holt IJ, Harding AE, Morgan-Hughes JA (1989) Deletions of muscle mitochondrial DNA in mitochondrial myopathies: sequence analysis and possible mechanisms. Nucleic Acids Res 17:4465-4469.

Holt IJ, Harding AE, Petty RK, Morgan-Hughes JA (1990) A new mitochondrial disease associated with mitochondrial DNA heteroplasmy. Am J Hum Genet 46:428-433.

Holyoake AJ, Sin IL, Benny PS, Sin FY (1999) Association of a novel human mtDNA ATPase6 mutation with immature sperm cells. Andrologia 31:339-345.

Homyk T, Sheppard DE (1977) Behavioral mutants of Drosophila melanogaster. I. Isolation and mapping of mutations which decrease flight ability. Genetics 87:95-104.

Huizing M (1998) Mitochondrial transmembrane carriers in mitochondriocytopathies. PhD thesis, University Nijmegen, The Netherlands.

Iborra FJ, Kimura H, Cook PR (2004) The functional organization of mitochondrial genomes in human cells. BMC Biol 2:9.

Jordens EZ, Palmieri L, Huizing M, van den Heuvel LP, Sengers RC, Dorner A, Ruitenbeek W, Trijbels FJ, Valsson J, Sigfusson G, Palmieri F, Smeitink JA (2002) Adenine nucleotide translocator 1 deficiency associated with Sengers syndrome. Ann Neurol 52:95-99.

Kaukonen J, Juselius JK, Tiranti V, Kyttala A, Zeviani M, Comi GP, Keranen S, Peltonen L, Suomalainen A (2000) Role of adenine nucleotide translocator 1 in mtDNA maintenance. Science 289:782-785.

Kawasaki F, Mattiuz AM, Ordway RW (1998) Synaptic physiology and ultrastructure in comatose mutants define an in vivo role for NSF in neurotransmitter release. J Neurosci 18:10241-10249.

Komaki H, Fukazawa T, Houzen H, Yoshida K, Nonaka I, Goto Y (2002) A novel D104G mutation in the adenine nucleotide translocator 1 gene in autosomal dominant progressive external ophthalmoplegia patients with mitochondrial DNA with multiple deletions. Ann Neurol 51:645-648.

Kretzschmar D, Hasan G, Sharma S, Heisenberg M, Benzer S (1997) The Swiss cheese mutant causes glial hyperwrapping and brain degeneration in Drosophila. J Neurosci 17:7425-7432.

Lamminen T, Majander A, Juvonen V, Wikstrom M, Aula P, Nikoskelainen E, Savontous ML (1995) A mitochondrial mutation at nt 9101 in the ATP synthase 6 gene associated with deficient oxidative phosphorylation in a family with Leber hereditary optic neuroretinopathy. Am J Hum Genet $56: 1238-1240$

Manfredi G (2001) Methods in cell biology. In: Mitochondria (Pon LA, Schon EA, eds), pp 133-145. San Diego: Academic.

Marin-Garcia J, Goldenthal MJ, Moe GW (2001) Mitochondrial pathology in cardiac failure. Cardiovasc Res 49:17-26.

Marko M, Leith A (1996) Sterecon-three-dimensional reconstructions from stereoscopic contouring. J Struct Biol 116:93-98.

Mattiazzi M, Vijayvergiya C, Gajewski CD, DeVivo DC, Lenaz G, Wiedmann M, Manfredi G (2004) The mtDNA T8993G (NARP) mutation results in an impairment of oxidative phosphorylation that can be improved by antioxidants. Hum Mol Genet 13:869-879.

Min KT, Benzer S (1997a) Spongecake and eggroll: two hereditary diseases 
in Drosophila resemble patterns of human brain degeneration. Curr Biol 7:885-888.

Min KT, Benzer S (1997b) Wolbachia, normally a symbiont of Drosophila, can be virulent, causing degeneration and early death. Proc Natl Acad Sci USA 94:10792-10796.

Min KT, Benzer S (1999) Preventing neurodegeneration in the Drosophila mutant bubblegum. Science 284:1985-1988.

Mita S, Rizzuto R, Moraes CT, Shanske S, Arnaudo E, Fabrizi GM, Koga Y, DiMauro S, Schon EA (1990) Recombination via flanking direct repeats is a major cause of large-scale deletions of human mitochondrial DNA. Nucleic Acids Res 18:561-567.

Mitchell P, Moyle J (1967) Chemiosmotic hypothesis of oxidative phosphorylation. Nature 213:137-139.

Moraes CT, DiMauro S, Zeviani M, Lombes A, Shanske S, Miranda AF, Nakase H, Bonilla E, Werneck LC, Servidei S, Nonaka I, Koga Y, Spiro AJ, Brownell KW, Schmidt B, Schotland DL, Zupanc M, DeVivo DC, Schon EA, Rowland LP (1989) Mitochondrial DNA deletions in progressive external ophthalmoplegia and Kearns-Sayre syndrome. N Engl J Med 320:1293-1299.

Napoli L, Bordoni A, Zeviani M, Hadjigeorgiou GM, Sciacco M, Tiranti V, Terentiou A, Moggio M, Papadimitriou A, Scarlato G, Comi GP (2001) A novel missense adenine nucleotide translocator-1 gene mutation in a Greek adPEO family. Neurology 57:2295-2298.

Nijtmans LG, Henderson NS, Attardi G, Holt IJ (2001) Impaired ATP synthase assembly associated with a mutation in the human ATP synthase subunit 6 gene. J Biol Chem 276:6755-6762.

Orth M, Schapira AH (2001) Mitochondria and degenerative disorders. Am J Med Genet 106:27-36.

Palladino MJ, Hadley TJ, Ganetzky B (2002) Temperature-sensitive paralytic mutants are enriched for those causing neurodegeneration in Drosophila. Genetics 161:1197-1208.

Palladino MJ, Bower JE, Kreber R, Ganetzky B (2003) Neural dysfunction and neurodegeneration in Drosophila $\mathrm{Na}^{+} / \mathrm{K}^{+}$ATPase $\alpha$ subunit mutants. J Neurosci 23:1276-1286.

Pallotti F, Baracca A, Hernandez-Rosa E, Walker WF, Solaini G, Lenaz G, Melzi D’Eril GV, Dimauro S, Schon EA, Davidson MM (2004) Biochemical analysis of respiratory function in cybrid cell lines harbouring mitochondrial DNA mutations. Biochem J 384:287-293.

Pastores GM, Santorelli FM, Shanske S, Gelb BD, Fyfe B, Wolfe D, Willner JP (1994) Leigh syndrome and hypertrophic cardiomyopathy in an infant with a mitochondrial DNA point mutation (T8993G). Am J Med Genet 50:265-271.

Paumard P, Vaillier J, Coulary B, Schaeffer J, Soubannier V, Mueller DM, Brethes D, di Rago JP, Velours J (2002) The ATP synthase is involved in generating mitochondrial cristae morphology. EMBO J 21:221-230.

Penczek P, Marko M, Buttle K, Frank J (1995) Double-tilt electron tomography. Ultramicroscopy 60:393-410.

Radermacher M (1992) Weighted back-projection methods, Ed 1. New York: Plenum.

Rastogi VK, Girvin ME (1999) Structural changes linked to proton translocation by subunit $\mathrm{c}$ of the ATP synthase. Nature 402:263-268.

Rogina B, Benzer S, Helfand SL (1997) Drosophila drop-dead mutations accelerate the time course of age-related markers. Proc Natl Acad Sci USA 94:6303-6306.

Santorelli FM, Shanske S, Jain KD, Tick D, Schon EA, DiMauro S (1994) A $\mathrm{T} \rightarrow \mathrm{C}$ mutation at nt 8993 of mitochondrial DNA in a child with Leigh syndrome. Neurology 44:972-974.

Satoh M, Kuroiwa T (1991) Organization of multiple nucleoids and DNA molecules in mitochondria of a human cell. Exp Cell Res 196:137-140.

Schapira AH, Cock HR (1999) Mitochondrial myopathies and encephalomyopathies. Eur J Clin Invest 29:886-898.

Scherer B, Klingenberg M (1974) Demonstration of the relationship between the adenine nucleotide carrier and the structural changes of mitochondria as induced by adenosine $5^{\prime}$-diphosphate. Biochemistry 13:161-170.

Schon EA, Manfredi G (2003) Neuronal degeneration and mitochondrial dysfunction. J Clin Invest 111:303-312.

Schon EA, Rizzuto R, Moraes CT, Nakase H, Zeviani M, DiMauro S (1989) A direct repeat is a hotspot for large-scale deletion of human mitochondrial DNA. Science 244:346-349.
Schon EA, Bonilla E, DiMauro S (1997) Mitochondrial DNA mutations and pathogenesis. J Bioenerg Biomembr 29:131-149.

Schon EA, Santra S, Pallotti F, Girvin ME (2001) Pathogenesis of primary defects in mitochondrial ATP synthesis. Semin Cell Dev Biol 12:441-448.

Sciacco M, Prelle A, D’Adda E, Lamperti C, Bordoni A, Rango M, Crimi M, Comi GP, Bresolin N, Moggio M (2003) Familial mtDNA T8993C transition causing both the NARP and the MILS phenotype in the same generation. A morphological, genetic and spectroscopic study. J Neurol 250:1498-1500.

Servidei S, Zeviani M, Manfredi G, Ricci E, Silvestri G, Bertini E, Gellera C, Di Mauro S, Di Donato S, Tonali P (1991) Dominantly inherited mitochondrial myopathy with multiple deletions of mitochondrial DNA: clinical, morphologic, and biochemical studies. Neurology 41:1053-1059.

Slautterback DB (1965) Mitochondria in cardiac muscle cells of the canary and some other birds. J Cell Biol 24:1-21.

Sligh JE, Levy SE, Waymire KG, Allard P, Dillehay DL, Nusinowitz S, Heckenlively JR, MacGregor GR, Wallace DC (2000) Maternal germ-line transmission of mutant mtDNAs from embryonic stem cell-derived chimeric mice. Proc Natl Acad Sci USA 97:14461-14466.

Stock D, Gibbons C, Arechaga I, Leslie AG, Walker JE (2000) The rotary mechanism of ATP synthase. Curr Opin Struct Biol 10:672-679.

Suomalainen A, Kaukonen J, Amati P, Timonen R, Haltia M, Weissenbach J, Zeviani M, Somer H, Peltonen L (1995) An autosomal locus predisposing to deletions of mitochondrial DNA. Nat Genet 9:146-151.

Suomalainen A, Majander A, Wallin M, Setala K, Kontula K, Leinonen H, Salmi T, Paetau A, Haltia M, Valanne L, Lonnqvist J, Peltonen L, Somer H (1997) Autosomal dominant progressive external ophthalmoplegia with multiple deletions of mtDNA: clinical, biochemical, and molecular genetic features of the 10q-linked disease. Neurology 48:1244-1253.

Tatuch Y, Christodoulou J, Feigenbaum A, Clarke JT, Wherret J, Smith C, Rudd N, Petrova-Benedict R, Robinson BH (1992) Heteroplasmic mtDNA mutation $(\mathrm{T} \rightarrow \mathrm{G})$ at 8993 can cause Leigh disease when the percentage of abnormal mtDNA is high. Am J Hum Genet 50:852-858.

Thyagarajan D, Shanske S, Vazquez-Memije M, De Vivo D, DiMauro S (1995) A novel mitochondrial ATPase 6 point mutation in familial bilateral striatal necrosis. Ann Neurol 38:468-472.

Trounce I, Neill S, Wallace DC (1994) Cytoplasmic transfer of the mtDNA nt $8993 \mathrm{~T} \rightarrow \mathrm{G}$ (ATP6) point mutation associated with Leigh syndrome into mtDNA-less cells demonstrates cosegregation with a decrease in state III respiration and ADP/O ratio. Proc Natl Acad Sci USA 91:8334-8338.

Van Goethem G, Dermaut B, Lofgren A, Martin JJ, Van Broeckhoven C (2001) Mutation of POLG is associated with progressive external ophthalmoplegia characterized by mtDNA deletions. Nat Genet 28:211-212.

Van Voorhies WA, Khazaeli AA, Curtsinger JW (2003) Selected contribution: long-lived Drosophila melanogaster lines exhibit normal metabolic rates. J Appl Physiol 95:2605-2613; discussion 2604.

Van Voorhies WA, Khazaeli AA, Curtsinger JW (2004) Testing the "rate of living" model: further evidence that longevity and metabolic rate are not inversely correlated in Drosophila melanogaster. J Appl Physiol 97:1915-1922.

Vergani L, Rossi R, Brierley CH, Hanna M, Holt IJ (1999) Introduction of heteroplasmic mitochondrial DNA (mtDNA) from a patient with NARP into two human rho degrees cell lines is associated either with selection and maintenance of NARP mutant mtDNA or failure to maintain mtDNA. Hum Mol Genet 8:1751-1755.

Walker JE (1995) Determination of the structures of respiratory enzyme complexes from mammalian mitochondria. Biochim Biophys Acta 1271:221-227.

White SL, Shanske S, McGill JJ, Mountain H, Geraghty MT, DiMauro S, Dahl HH, Thorburn DR (1999) Mitochondrial DNA mutations at nucleotide 8993 show a lack of tissue- or age-related variation. J Inherit Metab Dis 22:899-914.

Zeviani M, Servidei S, Gellera C, Bertini E, DiMauro S, DiDonato S (1989) An autosomal dominant disorder with multiple deletions of mitochondrial DNA starting at the D-loop region. Nature 339:309-311.

Zhang YQ, Roote J, Brogna S, Davis AW, Barbash DA, Nash D, Ashburner M (1999) Stress sensitive B encodes an adenine nucleotide translocase in Drosophila melanogaster. Genetics 153:891-903. 